\title{
Erratum: Striatal Volume Changes in the Rat Following Long-term Administration of Typical and Atypical Antipsychotic Drugs
}

In an article in the August issue [Andersson C, Hamer RM, Lawler CP, Mailman RB, Lieberman JA (2001): Striatal volume changes in the rat following long-term administration of typical and atypical antipsychotic drugs. Neuropsychopharmacology 27(2):143-151], the legend for Figure 3 on page 147 was mistakenly printed with an error. The legend should have read as follows:
Figure 3. Data illustrating the effects of the atypical antipsychotic agent olanzapine (OLZ) or vehicle (VEH) on caudateputamen volumes in animals treated for eight months. Data are expressed as means \pm S.E.M. Caudate-putamen volumes were significantly smaller in the olanzapine-treated animals versus vehicle-control animals $\left({ }^{*} \mathrm{p}<0.02\right.$; Bonferroni). 